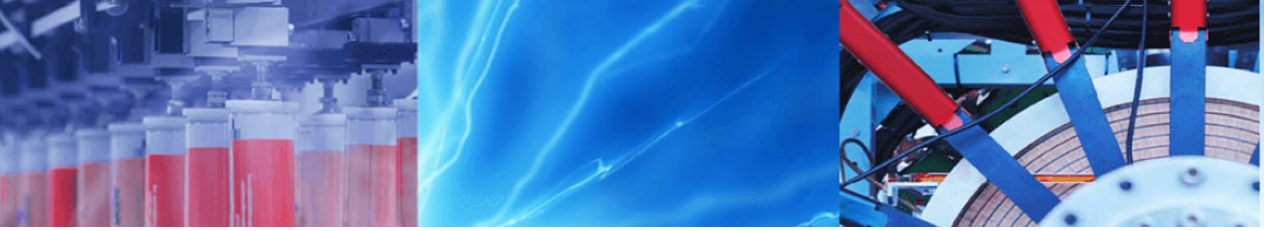

Research Article

\title{
Monitoring atmospheric water vapour variability over Nigeria from ERA-Interim and NCEP reanalysis data
}

\author{
Lazarus Mustapha Ojigi ${ }^{1} \cdot$ Yusuf Drisu Opaluwa²
}

(c) Springer Nature Switzerland AG 2019

\begin{abstract}
The spatial and temporal variability of water vapour in the atmosphere influences the earth weather, climate system, quality of spatial positioning and radio waves propagation of communications signals amongst others. It is therefore imperative to periodically monitor and map the water vapour phenomenon over specific areas of interest across the globe. This study therefore investigates the time-series variability of the atmospheric water vapour contents (AWVC) over Nigeria from the European Centre for Medium-Range Weather Forecasts (ECMWF) ERA-Interim (ERA-I) and National Centre for Environmental Prediction/National Centre for Atmospheric Research (NCEP/NCAR) reanalysis data. The 20072017 daily/monthly mean data sets of ERA-I and NCEP/NCAR were visualised and extracted with Panoply version 4.8.6 and MATLAB 2018b for the 37 states capital in Nigeria. The months of minimum and maximum AWVC for all sampled locations were determined and compared, and the best fit trend equations for six cities (one city from each of the six geopolitical zones) were developed. The monthly means of AWVC over the study area showed spatial heterogeneity trend. The latitudinal variations in both ERA-I and NCEP/NCAR data sets showed that AWVC over Nigeria increases as latitude decreases towards the equator, and vice versa, irrespective of the month or time of the year. The study showed that May-September and November-February of 2007-2017 represent the periods with highest and lowest values of AWVC over Nigeria, respectively, which are the expected wet and dry seasons in the study area, and with peak months of August and January, respectively. The linear regression of the ERA-I and NCEP/NCAR data sets gave a coefficient of correlation of about $96.37 \%$, coefficient of determination $\left(R^{2}\right)$ of about $92.9 \%$ and a coefficient of efficiency of $87.83 \%$, which indicate that ERA-I and NCEP/NCAR data sets have close values and the relationship between them in estimating AWVC over any selected location is statistically significant and valid. The coefficient of efficiency (E) of about $87.8 \%$ shows high level of internal efficiency of the ERA-I and NCEP/NCAR data sets used in this study. The best line of fit from polynomial models showed a range of the $R^{2}$ results for the best line-of-fit determination ranging between $78.36 \%$ and 95.75\% for ERA-I, and $81.24 \%$ and $94.13 \%$ for NCEP/NCAR. The models and time-series spatial maps of AWVC produced in the study are recommended for use in the empirical estimation of AWVC and validations of other independent water vapour retrieval solutions such as GNSS and aerospace radiometry over the study area.
\end{abstract}

Keywords Monitoring · Atmospheric $\mathrm{H}_{2} \mathrm{O}$ vapour · Variability · Reanalysis data · Trend analysis

\footnotetext{
$\bowtie$ Lazarus Mustapha Ojigi, drlazmojigi@gmail.com; Yusuf Drisu Opaluwa, opaluwayd@futminna.edu.ng| ${ }^{1}$ Department of Geomatics, Faculty of Environmental Design, Ahmadu Bello University, Zaria, Nigeria. ${ }^{2}$ Department of Surveying and Geoinformatics, School of Environmental Technology, Federal University of Technology, Minna, Nigeria.
}

SN Applied Sciences (2019) 1:1159 | https://doi.org/10.1007/s42452-019-1177-x

Received: 28 March 2019 / Accepted: 28 August 2019 / Published online: 5 September 2019 


\section{Introduction}

The atmospheric water vapour is very important for the Earth system and significantly influences many processes of the earth's weather and climate; hence, its variability is key to understanding the hydrological cycle $[44,64,65]$. Water vapour is the most important natural greenhouse gas and the dominant source of infrared opacity in the clear-sky atmosphere $[52,61]$, and its fast-acting feedbacks constitute a strong amplification mechanism for anthropogenic climate change $[28,57]$, thus also making water vapour a key parameter for earth energy budget and climate change analysis [57]. It is more effective at absorbing the thermal radiation from the Earth's surface than carbon dioxide though its molecule does not stay or linger in the atmosphere as long as a carbon dioxide molecule does before falling back to the earth as precipitation $[52,66]$.

Basically, atmospheric water vapour is formed through the processes of transpiration in plants, heatinduced evaporations from water, ice, surface of streams, lakes, rivers and oceans into the atmosphere. In recent years, the burnings of petroleum products and natural gas have become a notable anthropogenic cause of water vapour variations in the atmosphere, thereby contributing to local climate variability and global warming. For instance, in the Niger Delta Region of Nigeria, gas flaring and burning of all petroleum refineries have become notable phenomena capable of modifying the local climate of the region. Water vapour varies by volume in the atmosphere from a trace to about $4 \%$. Therefore, on average, only about $2-3 \%$ of the molecules in the air are water vapour molecules [26]. The amount of water vapour in the air is small in extremely arid areas and in location where the temperatures are very low. A $10 \%$ drop in water vapour, $16 \mathrm{~km}$ up, has had an effect on global warming between 2000 and 2010 [1]. Amongst other greenhouse gases such as carbon dioxide and methane, water vapour has a much higher temporal and spatial variability [64]. The amount of water vapour is highly variable being a function of temperature and of atmospheric conditions, and its main effect is measured in a broadened band around the $\mathrm{H}_{2} \mathrm{O}$ absorption line at $22.2 \mathrm{GHz}$ [50]. The attenuation due to water vapour exhibits noticeable daily, seasonal and geographical variations.

The global average of atmospheric water vapour contents has increased since 1980, but in Nigeria, the average atmospheric water vapour has been more favourably consistent in the northern part than in the south [9]. Though the water vapour lapse rate feedback is believed to be robustly represented in climate models, there is still high uncertainty on water vapour trends, especially at a regional level [11].

\subsection{Effects of water vapour on satellite signals}

For satellite surveying, remote sensing, navigation and communications, existence of atmospheric water vapour has random and systematic effects on radio signals at various frequencies of transmission, leading to errors in positioning, magnitude and phase data sets and signal attenuations, amongst others. Microwave signals transmitted by global positioning system (GPS) satellites are increasingly used for high-accuracy scientific applications including studies of weather, climate, crustal deformation, plate tectonics, sea level, ice dynamics and isostasy [59], but these signals are often impaired by vapour contents in the atmosphere.

The uncondensed water vapour and oxygen can be strongly absorptive of radio signals, especially at millimetre-wave frequencies and higher frequencies (tens to hundreds of $\mathrm{GHz}$ ), and their attenuation or absorption constant is defined in the units of $\mathrm{dB} / \mathrm{km}$ [30]. Atmospheric gases are the major factors that affect signal impairment of satellite-to-ground and ground-to-satellite links at frequencies C-band (6/4 GHz), Ku-band (14/12 GHz), Ka-band $(30 / 20 \mathrm{GHz})$ and $\mathrm{V}$-band $(50 / 40 \mathrm{GHz})[6,7]$. According to Al-Saegh [8],

The gases attenuation at fixed $40 \% \mathrm{RH}$ reached higher level at approximately $325 \mathrm{GHz}$. The relative humidity $(\mathrm{RH})$ is directly proportional to the amount of signal power attenuation due to the water vapour particles in space, and hence the total gases attenuation as shown in Fig. 1 b. However, the regions near the sea and the equator usually suffer from higher $\mathrm{RH}$ which indicates increased gases attenuation.

Water is believed to, amongst other gases, exert significant effects on satellite signals through phenomena such as refraction (a change in the direction of propagation of a radio wave due to the variation in refractive index of the medium), absorption (a decrease in the amplitude of a radio wave caused by an irreversible conversion of energy from the radio wave to matter in the propagation path), scattering (a process in which the energy of a radio wave is dispersed due to interaction with elements in the medium), diffraction (a change in the direction of propagation of a radio wave resulting from the presence of an obstacle, a restricted aperture or other objects in the medium), multipath (when a transmitted radio wave reaching the receiving antenna by two or more propagation paths), scintillation (rapid variations or fluctuations of the amplitude and the phase of a radio wave caused by small-scale irregularities in the transmission path/paths 


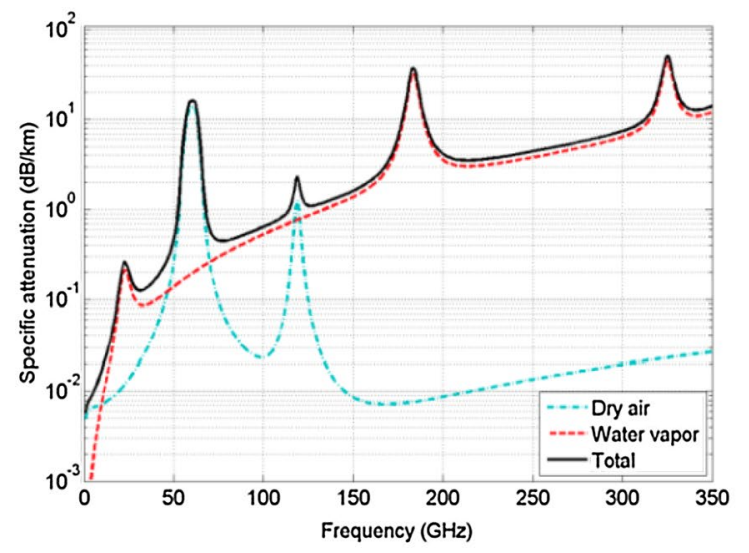

(a)

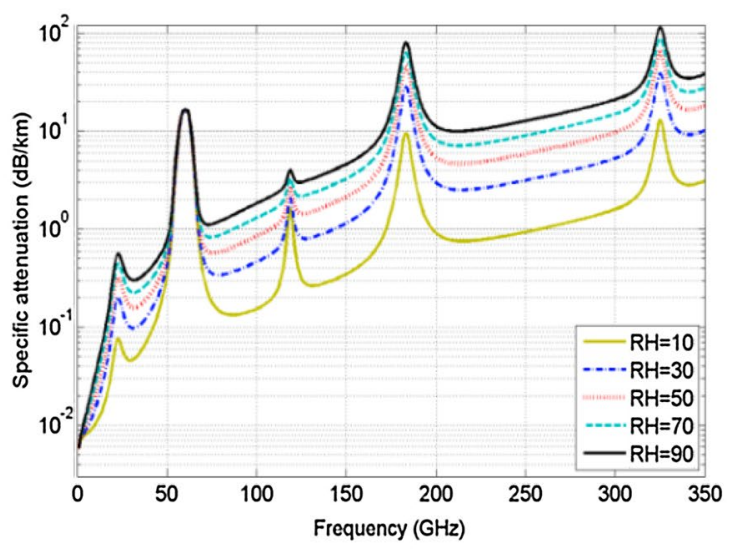

(b)

Fig. 1 Gases attenuation [8]

with time and fading (the slower variation in the amplitude or field strength of a radio wave caused by changes in the transmission path(s) with time) [33].

In view of the implications of atmospheric $\mathrm{H}_{2} \mathrm{O}$ vapour in geodesy and geosciences, atmospheric and radio sciences and meteorology, the global water vapour data sensors are now key components of earth observation and weather satellites, satellite radar altimetry and radiometry, etc., for the monitoring and prediction of global and regional climate processes and dynamics. A variety of systems exist for measuring the atmospheric integrated water vapour (IWV), e.g. radiosondes [54], microwave radiometry [22], very long baseline interferometry (VLBI) [29] and global navigation satellite systems (GNSS) [15]. However, various methods have their respective peculiarities.

\subsection{An overview of satellite radiometer water vapour retrieval and data availability}

Since 1979, passive radiometers have been working in the infrared band, but their observations are of low accuracy and limited to clear-sky conditions $[16,19]$. These have been largely overcome by the multimission satellite altimetry microwave radiometers now used for global measurement of water vapour contents. Humidity measurements from downward-looking microwave radiometers are independent of the cloud coverage and provide high accuracy over the oceans in nonprecipitating atmospheres [60]. However, over land and ice surfaces, the accuracy of the water vapour estimated from these microwave radiometers is degraded because of assumptions that have to be made about surface emissivity [20, 38, 40,67].

It is therefore expected that if water vapour estimation from satellite altimetry microwave radiometer is at the level of the tropopause or the atmosphere $(\sim 10 \mathrm{~km}$ above the $\mathrm{msl}$ ), the suspicious effect of land surface emissivity and contamination of the radar echoes (waveforms) is minimal and has less or minimal impact on the accuracy of the estimation. Previously, on water vapour data, numerical weather prediction (NWP) models were originally based on radiosonde observations, but today satellite observations from infrared and microwave radiometers are also operationally assimilated into the NWP and reanalysis models $[10,37,39,48]$.

Before now, large radiosonde data gaps over the oceans, and over some land areas of Africa, limit the ability to define the global water vapour distribution. However, the birth of newer data sources, such as the data sets from infrared and microwave satellite sensors, contributes to the enhanced global coverage on daily basis [53]. Examples of available large-scale water vapour data sets include satellite microwave retrievals from the Defense Meteorological Satellite Program (DMSP) Special Sensor Microwave Imager (SSM/I) data over ocean [35].

Television Infrared Observation Satellite (TIROS) Operational Vertical Sounder (TOVS) infrared retrievals over land $[55,68]$, upper-tropospheric relative humidity from geostationary satellite [30], and a number of data sets using special radiosonde measurements for research purposes on limited time and space scales. Other data sets include model-analysed 4D data-assimilated global humidity fields from the European Centre for Medium-Range Weather Forecasts (ECMWF) and National Centers for Environmental Prediction (NCEP) [62]. The ERA-I initiated in 2006 is the latest global atmospheric reanalysis produced by the ECMWF to provide a bridge between ECMWF's previous reanalysis, ERA-40 (1957-2002) and the next-generation extended reanalysis $[14,21]$. The reanalysis data sets are integrated outputs from multistage and multisensor satellite observations. Schröder et al. [57] made excellent summaries of the main passive microwave satellite sensors (imagers and sounders) used for global water vapour 
and the existing satellite and reanalysis data records, respectively.

\subsection{Multisatellite radiometry data sources}

Multisatellite data refer to integrated data models or outputs from various satellites placed in different orbits and elevations; hence, the ERA-I and NCEP data sets used in this study are products of multistage and multisensor satellite observations. Some of such multisensor technologies include the advanced infrared sounder (AIRS), radiosondes, microwave radiometers and other passive microwave satellite sensors, VLBI, TIROS-TOVS, Moderate Resolution Imaging Spectroradiometer (MODIS), Advanced Spaceborne Thermal Emission and Reflection Radiometer (ASTER), GOES-R Series, Meteosat, NOAA-Advanced Very High Resolution Radiometer (NOAA-AVHRR), Aqua, Tropical Rainfall Measuring Mission (TRMM), GPS/GNSS, etc. The GNSS-based water vapour data are, however, not usually included in ECMWF (ERA-I and ERA5), NCEP and other atmospheric reanalysis data models, but could be used for data validations at selected local points of interest.

The availability of multisatellite radiometry for the observations, retrievals and assimilation of atmospheric water vapour content presents unique opportunity for atmospheric science and climate change researches in developing countries that are not in a position to generate such data sets for their own use. This is because the accurate knowledge of the contents, patterns, spatial and temporal variability of water vapour is indispensable for the investigations and descriptions of regional weather and climate processes, wet refractivity analysis over spatial locations, error budget in positioning and navigation and estimation of attenuation constants of radio waves propagation of satellite signals over selected communication antennae or geodetic observatory, etc. This study therefore investigates the time-series variability of atmospheric water vapour contents over Nigeria from the ERA-I and NCEP/NCAR reanalysis data, with a view to create spatial and empirical estimating models for AWVC over selected locations and baselines in Nigeria. The objectives of this study are to:

1. Map the spatio-temporal variability of AWVC over 37 capital city locations in Nigeria from ERA-I and NCEP/ NCAR data (2007-2017).

2. Determine the trend and the periods/months of maximum and minimum AWVC regime over the study area.

3. Determine the statistical relationship between the spatially co-located AWVC values from ERA-I and NCEP/ NCAR data.

4. Identify the implications of the trend of atmospheric water vapour variability on satellite surveying/posi- tioning and communications, and climate change in Nigeria.

\subsection{The climate of Nigeria}

According to $[47,49]$, the climate of Nigeria is largely influenced by three major atmospheric phenomena, namely: the maritime tropical (MT) air mass, the continental tropical (cT) air mass and the equatorial easterlies. The hot, dry continental air masses originating from the high-pressure system above the Sahara Desert give rise to dusty Harmattan winds over the Sahel and Savannah Region of West Africa from November to February, while in summer, moist equatorial air masses originating over the Atlantic Ocean bring annual monsoon rains [43].

Pokam et al. [51] observed that the interannual variability of moisture flux in equatorial central region of Africa is contributed mainly by the low-level moisture advected from the Atlantic Ocean, underlying its crucial role for the regional climate. Over Nigeria, and elsewhere in West Africa, precipitation decreases with increase in latitudes and hence becomes progressively drier as one moves north from the coast [63]. Figure 2a shows the surface area satellite image of the relatively dry Sahel northern and rainforest southern parts of Nigeria, and Fig. $2 b$ illustrates the satellite signal attenuation morphology by atmospheric gases (e.g. water vapour).

\section{Materials and methods}

\subsection{Data and sources}

Two sets of data sets were acquired and used for the timeseries monitoring of water vapour variability over Nigeria. Table 1 contains the properties of the ERA-Interim and NCEP satellite reanalysis data records. The ERA-I is a global atmospheric reanalysis produced by the ECMWF, and the data exist either in GRIB or NetCDF format, downloadable from ECMWF website. The global fields are available at full resolution, both vertically (on model levels) and horizontally, and data retrievals can be optionally restricted to a limited area and interpolated to a coarser grid [13]. The pair of ERA-I and NCEP data sets were selected for this study, considering their spatial grid resolutions, ERA-I $\left(0.75^{\circ}\right)$ and NCEP/NCAR $\left(2.5^{\circ}\right)$, when compared to ERA5 HRES $\left(31 \mathrm{~km} / 0.28125^{\circ}\right)$. Secondly, with the pair of ERA-I and NCEP, there is reduced spatial interpolation ratios between the two data sets, which is not likely with the pair of ERA5 and NCEP data sets.

Reanalysis systems are typically based on advanced operational atmospheric general circulation models and include data assimilation schemes. The data assimilation 


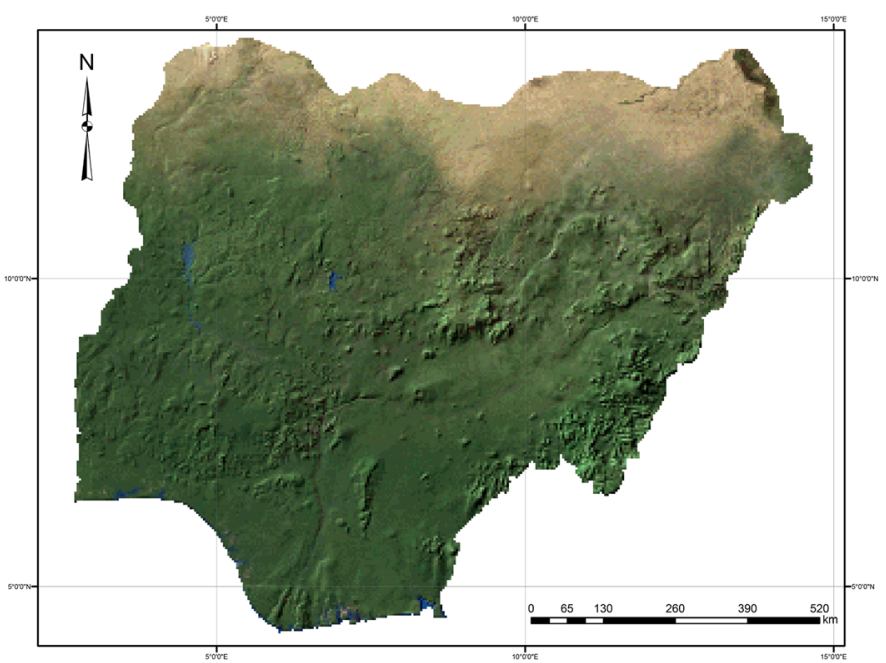

(a)

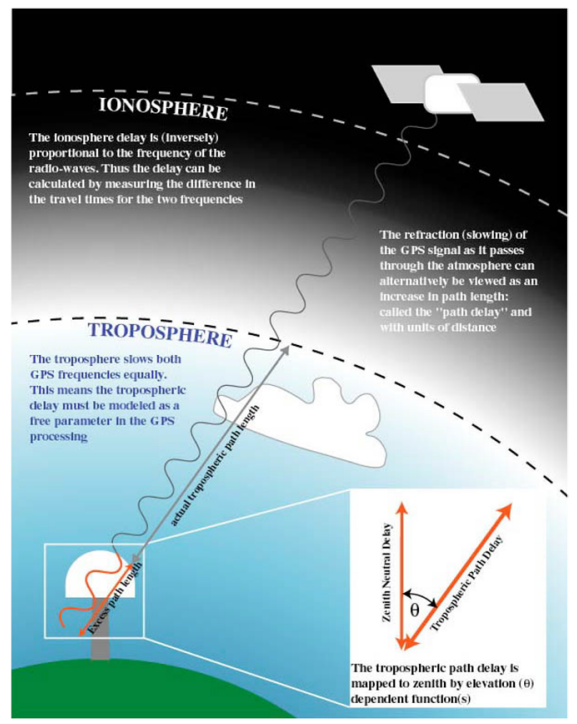

(b)

Fig. 2 a Image of Nigeria [23]; $\mathbf{b}$ tropospheric signal delays [25]

Table 1 Satellite reanalysis data records used and source(s)

\begin{tabular}{|c|c|c|c|c|c|}
\hline Product technique & $\begin{array}{l}\text { Data record and file } \\
\text { type }\end{array}$ & Parameters/units & $\begin{array}{l}\text { Spatial/temporal resolu- } \\
\text { tion }\end{array}$ & $\begin{array}{l}\text { Spatial/temporal cover- } \\
\text { age/extent }\end{array}$ & Source of data \\
\hline Reanalysis & $\begin{array}{l}\text { ERA-I } \\
\text { NetCDF-3 }\end{array}$ & $\begin{array}{l}\text { Monthly mean TCWV/ } \\
\mathrm{kg} / \mathrm{m}^{2}\end{array}$ & $\left(0.75^{\circ} \times 0.75^{\circ}\right)$ grid & $\begin{array}{l}\text { Global } \\
\text { January } 2007-2017 \\
\text { Nigeria (long. } \\
2.675 \mathrm{E}-14.675 \mathrm{E} \text { and } \\
\text { lat. } 13.925 \mathrm{~N}-4.225 \mathrm{~N}]\end{array}$ & ${ }^{*}$ ECMWF \\
\hline Reanalysis & $\begin{array}{l}\text { NCEP-NCAR-derived } \\
\text { products } \\
\text { NetCDF }\end{array}$ & $\begin{array}{l}\text { Monthly mean PW } \\
\text { contents } \mathrm{kg} / \mathrm{m}^{2}\end{array}$ & $\begin{array}{l}\left(2.5^{\circ} \times 2.5^{\circ}\right) \\
\text { grid }\end{array}$ & $\begin{array}{l}\text { Global } \\
\text { January 2007-2017 } \\
\text { Nigeria (long. } \\
\text { 2.675E-14.675E and } \\
\text { lat. } 13.925 \mathrm{~N}-4.225 \mathrm{~N}]\end{array}$ & ${ }^{* *}$ NCEP-NCAR \\
\hline
\end{tabular}

*http://apps.ecmwf.int/datasets/data/interim-full-moda/levtype=sfc/

**http://www.esrl.noaa.gov/psd/data/gridded/data.ncep.reanalysis.derived.html

merges spatially and temporally discontinuous observations with model state fields to reinitialise atmospheric forecasts and produce spatially and temporally continuous state fields [57]. The vertically integrated variables for water vapour from ECMWF are given Eq. (1) [13, 14]:

$\mathrm{TCWV}=\frac{1}{g} \int_{0}^{1} g \frac{\partial p}{\partial \eta} \mathrm{d} \eta$

TCWV = total column water vapour, $p$ is specific humidity on model levels, $\eta$ is pressure of the model levels and $\mathrm{g}$ is gravitational acceleration.

Information about the current status of ERA-I production, availability of data online and near-real-time updates of various climate indicators can be found in http://www. ecmwf.int/research/era. On the other hand, information on gridded data from NCEP, National Oceanic and Atmospheric Administration (NOAA) can be found in the following website http://www.esrl.noaa.gov/psd/data/gridded/ data.ncep.reanalysis.derived.html.

\subsection{Methods}

Figure 3 shows the flow diagram for the methodology adopted for the time-series mapping (TSM) of the AWVC over Nigeria. The flow diagram is made up of retrievals of NetCDF data, data pre-processing (reading and extracting of area of interest (AOI) arrays and the spatial sorting of arrays-lat/long), data processing and TSM (import, interpolation/resampling, AWVC computations, spatial and latitudinal variation mapping) and analysis and modelling techniques. 


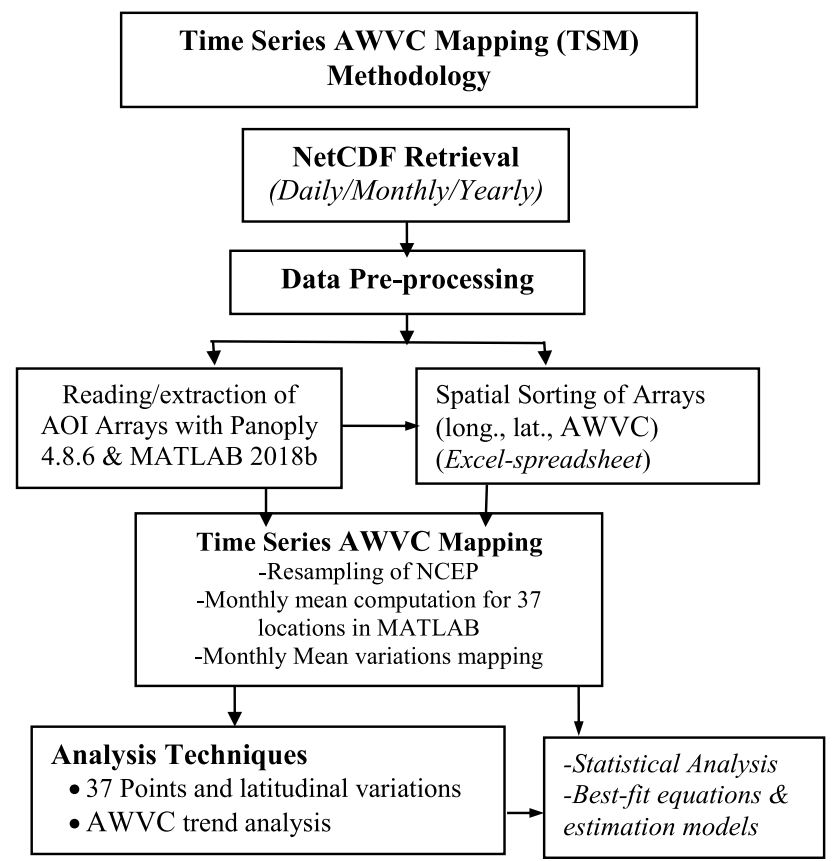

Fig. 3 Flow diagram for the TSM of AWVC over Nigeria

\subsection{Data processing and time-series mapping}

The NCEP data in $2.5 \times 2.5$ decimal degree grid were resampled to $0.75 \times 0.75$ decimal degree grid to the equivalent of the spatial resolution of the ECMWF/ERA-I data. The kriging interpolation technique was adopted in view of its anisotropic and geometric output advantages over other techniques. The kriging interpolation algorithm produces an unbiased prediction, calculates the spatial distribution of uncertainty and allows for the estimation of the errors in an interpolation for any particular point $[12,17,42,46]$. The spatio-temporal water vapour and climatological maps of the study area (ERA-I and NCEP/NCAR, respectively) were produced for the period of 2007-2017.

\subsection{AWVC trend and statistical analysis techniques}

Two fitting trend models were tested for predicting the AWVC over 37 cities in Nigeria. The models include polynomial and moving average models. Considering the geometry of the monthly mean per station, the criteria for selecting best fit model include the best-fit trend line and the coefficient of determination $\left(R^{2}\right)$. Considering the number of locations and the geopolitical zones of Nigeria, six city locations were randomly selected for the fitting trend models in this study. The selected cities include Damaturu (north-east), Birnin Kebbi (north-west), Lafia (north-central), Oshogbo (south-west), Enugu (south-east) and Port Harcourt (south-south).
Polynomial model

A polynomial model is a mathematical formula or expression with several algebraic terms. It is given by:

$y=2 x^{2}+2 x^{3}+1$

where $y\left(\mathrm{~kg} / \mathrm{m}^{2}\right)$ represents the vapour value and $x$ represents the period of month.

Moving average model is given in the form of Eq. (3).

$F_{t}=\frac{A_{t-1}+A_{t-2}+A_{t-3}+\cdots+A_{t-n}}{n}$

where $F_{t}=$ forecast for the coming period, $n=$ number of periods averaged and $A_{t-1}=$ actual values of the previous period for up to ' $n$ ' period.

The statistical analysis considered in this study includes root-mean-square error (RMSE), mean absolute error (MAE), mean absolute relative error (MARE), model efficiency (MEF), correlation coefficient $(r)$, coefficient of determination $\left(R^{2}\right)$ /adjusted-r, (MaxAE) and the maximum absolute relative error (MaxARE). The mean absolute error (MAE) measures the absolute deviation of the atmospheric water vapour values of ERA-Interim and NCEP/NCAR. In Eqs. (2) to (11), the ERA-Interim and NCEP/NCAR data sets are assigned predicted $\left(x_{i}\right)$ and observed $\left(y_{i}\right)$ data, respectively, and $n$ represents the number of observations [20, 56].

To find out how much of a difference exists between the predicted $\left(x_{i}\right)$ and observed $\left(y_{i}\right)$ values, there is a need to calculate the mean absolute error (MAE) of the data [24]. The root-mean-square error (RMSE) of the predicted $\left(x_{i}\right)$ and observed $\left(y_{i}\right)$ data sets is the average magnitude of the error in the set of observation(s), which can be calculated by Eq. (5). RMSE is stated in the same units of the original measurements [18]:

$\operatorname{MAE}=\frac{\left(\sum_{i=1}^{n}\left|x_{i}-y_{i}\right|\right)}{n}$

RMSE $=\sqrt{\frac{1}{n} \sum_{i=1}^{n}\left(x_{i}-y_{i}\right)^{2}}$

The mean absolute relative error (MARE) is the average of the absolute deviations between the predicted $\left(x_{i}\right)$ and observed $\left(y_{i}\right)$ values. The MARE can be estimated by (6) $[34,58]$ :

MARE $=\frac{\sum_{i=1}^{n} \frac{\left|x_{i}-y_{i}\right|}{y_{i}}}{n}$

Coefficient of efficiency (CEF) $[32,58]$ is also referred to as model efficiency (MEF) $[41,58]$, which is a measure of the internal efficiency of predicted and observed data, as the 
ratio of the ideal numbers of the data sets over the period can be estimated by Eq. (7). The designated predicted and observed terms in this study have been defined earlier, while $\hat{x}$ and $\hat{y}$ are the mean of the designated predicted and observed atmospheric water vapour data, respectively:

$\mathrm{MEF}=1-\frac{\sum_{i=1}^{n}\left(x_{i}-y_{i}\right)^{2}}{\sum_{i=1}^{n}\left(\left|\left(x_{i}-\hat{x}\right)\right|-\left|\left(y_{i}-\hat{y}\right)\right|\right)^{2}}$

The correlation coefficient ( $r$ ) is represented by Eq. (8), while the coefficient of determination $\left(R^{2}\right)$ or adjusted- $r$ is the square of the correlation coefficient and represented by Eq. (9):

$$
\begin{aligned}
& r=\frac{\sum_{i=1}^{n}\left(x_{i}-\hat{x}\right)\left(y_{i}-\hat{y}\right)}{\left[\sum_{i=1}^{n}\left(x_{i}-\hat{x}\right)^{2} \cdot \sum_{i=1}^{n}\left(y_{i}-\hat{y}\right)^{2}\right]^{1 / 2}} \\
& R^{2}=\left[\frac{\sum_{i=1}^{n}\left(x_{i}-\hat{x}\right)\left(y_{i}-\hat{y}\right)}{\left[\sum_{i=1}^{n}\left(x_{i}-\hat{x}\right)^{2} \cdot \sum_{i=1}^{n}\left(y_{i}-\hat{y}\right)^{2}\right]^{1 / 2}}\right]^{2}
\end{aligned}
$$

The maximum absolute error (MaxAE) could be referred to as the maximum absolute difference between the between the predicted $\left(x_{i}\right)$ and observed $\left(y_{i}\right)$ values, which can be represented by Eq. (10):

$\operatorname{MaxAE}=V_{i=1}^{n}\left|x_{i}-y_{i}\right|$
Therefore, the estimation of the maximum absolute relative error (MaxARE) (11) can be inferred from Eq. (3):

$\operatorname{MaxARE}=\frac{V_{i=1}^{n}\left|x_{i}-y_{i}\right|}{y_{i}}$

Coefficient of efficiency (CEF) also referred to as model efficiency (MEF) [41] is a measure of the internal efficiency of the predicted and observed data, as the ratio of the ideal numbers of the data sets over the period $[31,58]$. Therefore, the closer the CEF to 1 (or 100\%), the higher the overall level of internal efficiency of the predicted and observed data.

\section{Results and discussions}

Figures $4 a-I$ and $5 a-I$ show the monthly mean spatial maps of AWVC over 37 capital city locations in Nigeria (2007-2017) from ERA-I and NCEP/NCAR data sets, respectively. The 36 state capitals and Abuja selected for the study fall into six geopolitical zones, namely northwest, north-east, north-central, south-west, south-east and south-south, which are considered to have geographical contiguity and similar climate.

Figure $6 a, b$ is made up of 37 graphs representing each capital city's monthly mean values of AWVC. The geometry of the graphs indicates a peak period between the months of July and September. The linear trend of each of the locations across the months can be further derived or deduced. Figure $7 a, b$ shows the average
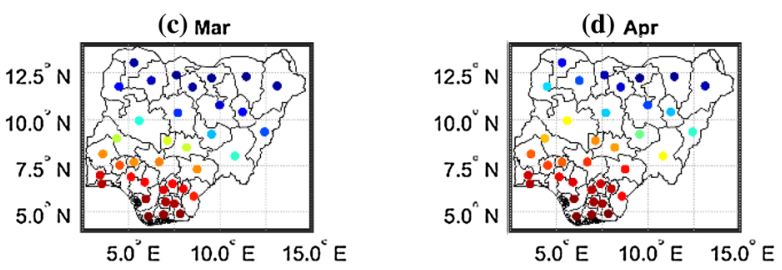

(g) Jul
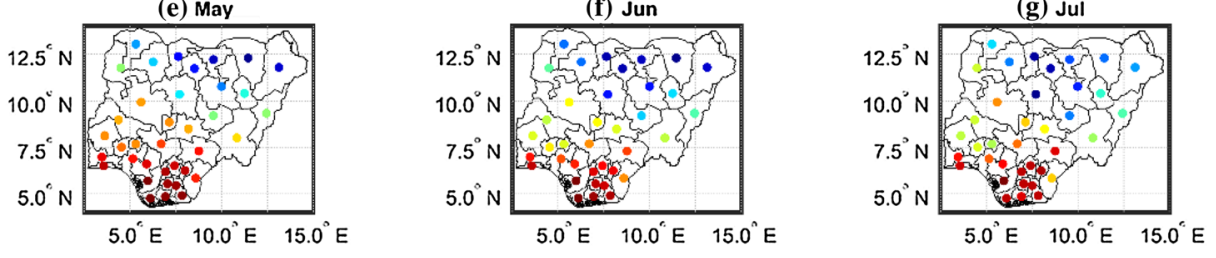

(i) Sep

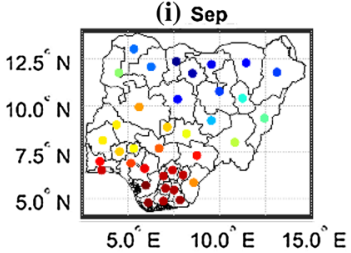

(k) Nov

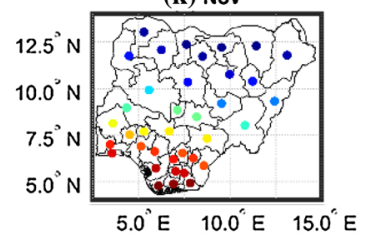

(h) Aug

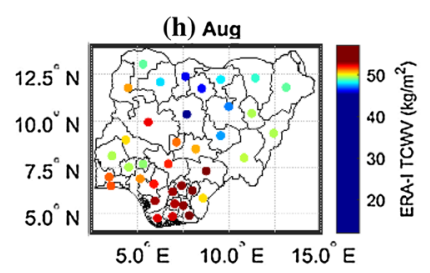

(I) Dec

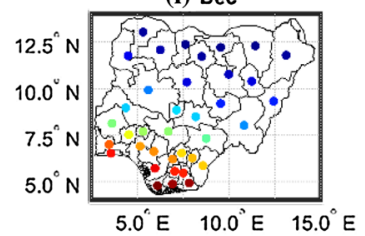

Fig. 4 Monthly mean of ERA-Interim atmospheric water vapour $\left(\mathrm{kg} / \mathrm{m}^{2}\right)$ over 37 city locations in Nigeria for the years 2007-2017 


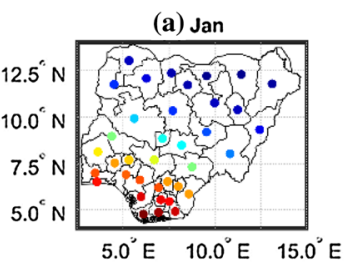

(e) May

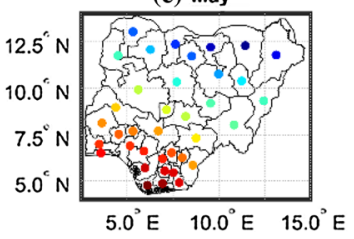

(i) Sep

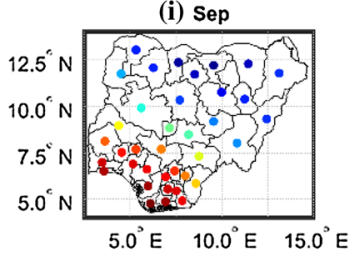

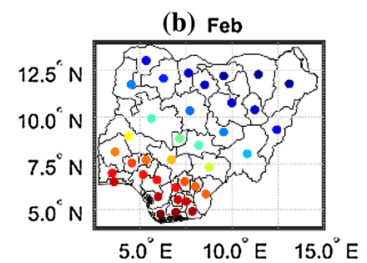

(f) Jun
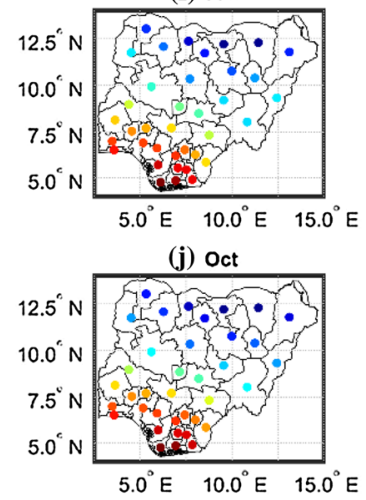

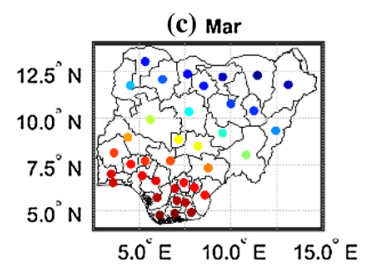

(g) Jul

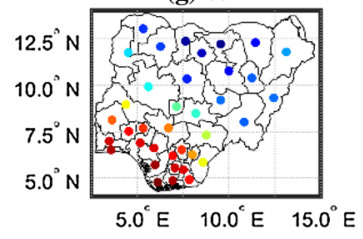

(k) Nov

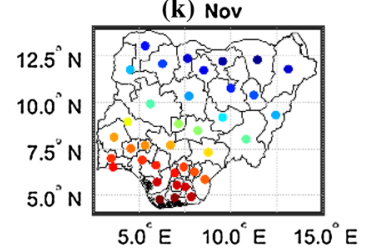

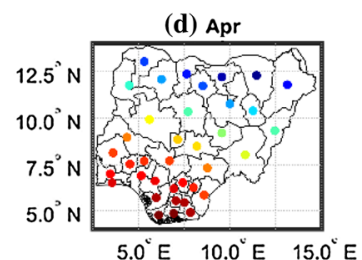

(h) Aug

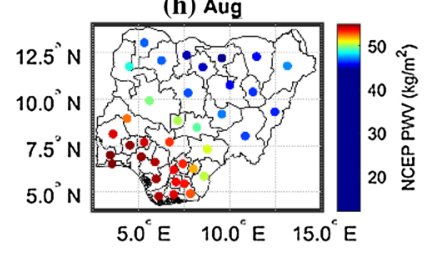

(l) Dec

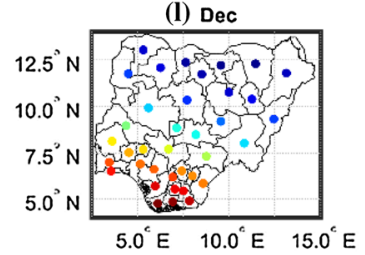

Fig. 5 Monthly mean of NCEP/NCAR atmospheric water vapour $\left(\mathrm{kg} / \mathrm{m}^{2}\right)$ over 37 city locations in Nigeria (2007-2017)

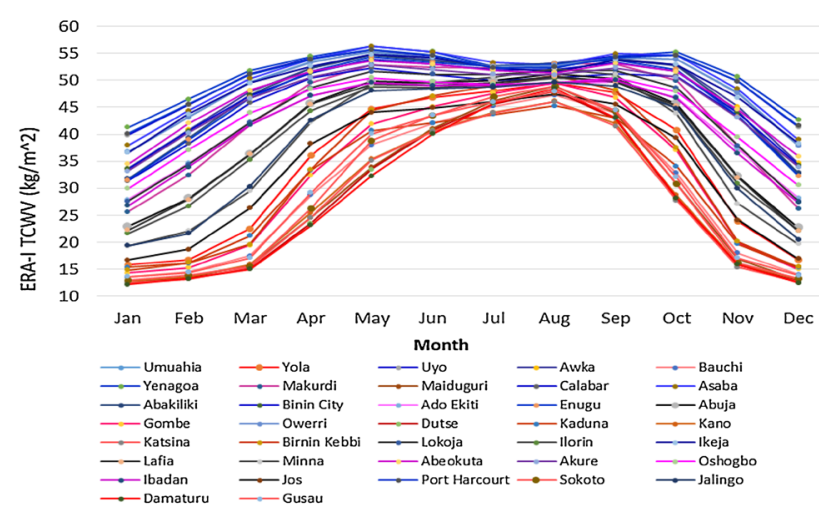

(a) ERA-I

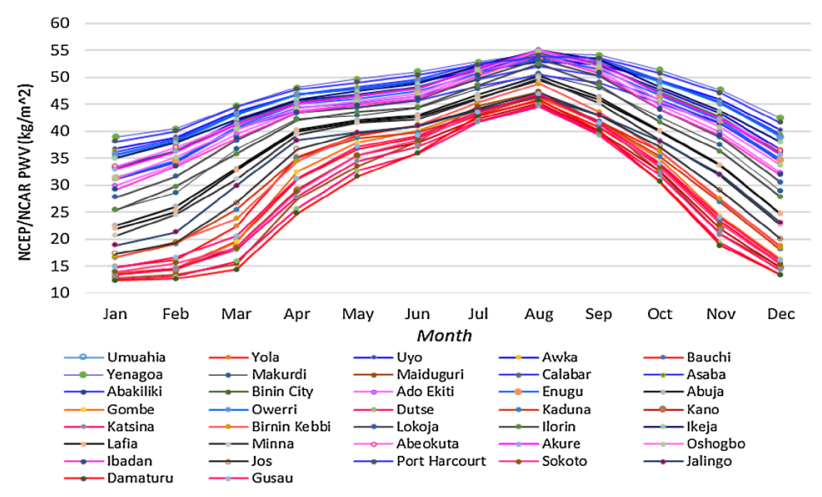

(b) NCEP/NCAR

Fig. 6 Monthly average AWVC $\left(\mathrm{kg} / \mathrm{m}^{2}\right)$ for 37 selected cities in Nigeria

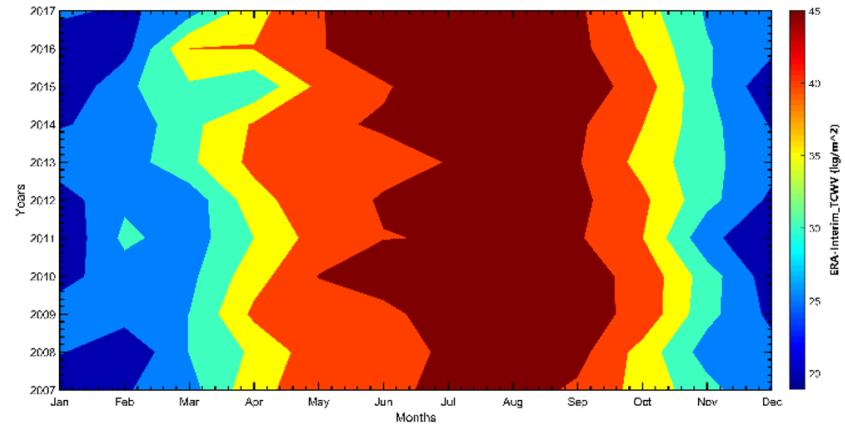

(a) ERA-I

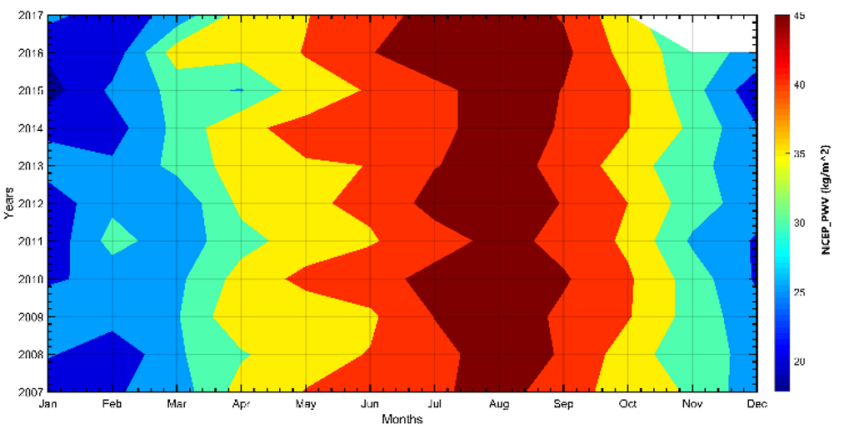

(b) NCEP/NCAR

Fig. 7 Monthly mean of variations in atmospheric water vapour content $\left(\mathrm{kg} / \mathrm{m}^{2}\right)$ over Nigeria (2007-2017) 
AWVC variations for months/years (January-December, 2007-2017), giving a general outlook of the climatology of water vapour regime over Nigeria for the entire period of study with both ERA-I and NCEP/NCAR data sets. On the other hand, Fig. 8a, b depicts the latitudinal variations of AWVC over Nigeria.

Figure 8a indicates two peaks of AWVC over the study area, while Fig. 9 shows the separated AWVC peak patterns over Nigeria (combined in Fig. 4a). The stations in the north (NW, NE and NC) exhibited unimodal peak in the month of August in both data sets, while stations in the south (SW, SE and SS) exhibited bimodal peak pattern in the months of May and August with ERA-I and NCEP/NCAR data, respectively (further outlined in Table 2).

Table 2 contains the minimum and maximum monthly mean AWVC over all 37 selected capital cities, grouped into geopolitical zones in Nigeria with both ERA-I and NCEP/NCAR data sets, while Table 3 is the zonal average of the minimum and maximum monthly mean values of AWVC over Nigeria.

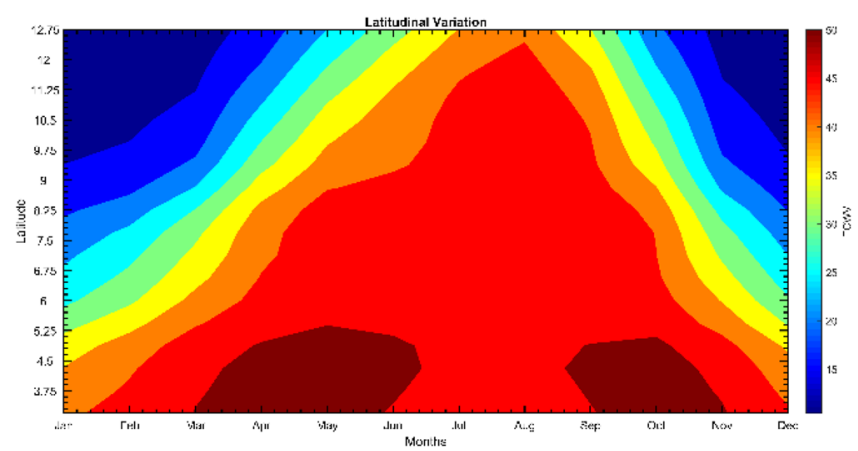

(a) ERA-I

\subsection{Data metric performance index}

The least square linear regression obtained for the NCEP/ NCAR precipitable water vapour (PWV) and ERA-I total column water vapour (TCWV) data sets over Nigeria for 2007-2017 is shown in Fig. 10. The total data sample (N) was 42120, and the linear relationship between the ERA-I and NCEP/NCAR data sets is given by Eqs. 12 and 13, respectively. Table 4 presents the summary of the result of the statistical performance index (error measures) of the data sets:

$\mathrm{TCWV}=1.126 \times \mathrm{PWV}-3.400$

$\therefore P W V=\frac{(T C W V+3.4)}{1.126}$

The computed coefficient of correlation $(r)$ of about $0.964(\sim 96.4 \%)$ and the coefficient of determination $\left(R^{2}\right)$ $0.929(\sim 92.9 \%)$ indicate that the relationship between the two data sets (ERA-I and NCEP/NCAR) for estimating AWVC over any selected location in the study area is statistically significant and valid.

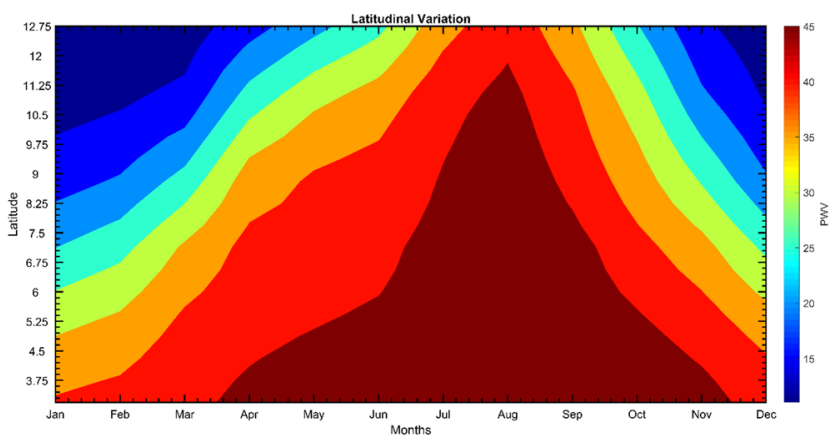

(b) NCEP/NCAR

Fig. 8 Latitudinal variations in atmospheric water vapour contents over Nigeria

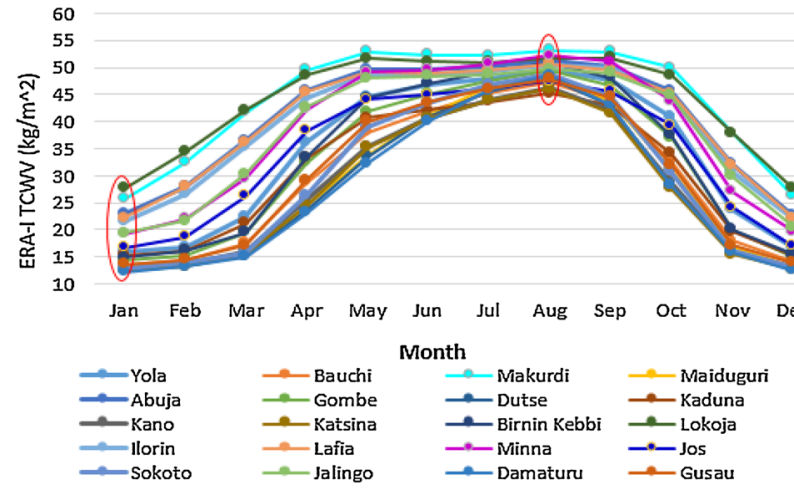

(a) Northern Stations

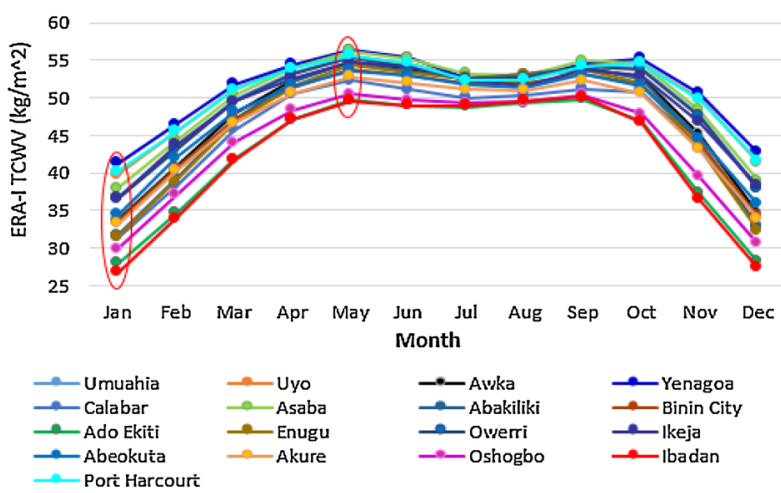

(b) Southern Stations

Fig. 9 ERA-I separated AWVC peak patterns over Nigeria 
Table 2 Minimum/maximum monthly mean AWVC over 37 selected locations in Nigeria (2007-2017)

\begin{tabular}{|c|c|c|c|c|c|c|}
\hline \multirow[t]{2}{*}{ Geopolitical zone/city } & \multicolumn{3}{|l|}{ ERA-I } & \multicolumn{3}{|c|}{ NCEP/NCAR } \\
\hline & $\begin{array}{l}\min \_a w v c \\
\left(\mathrm{~kg} / \mathrm{m}^{2}\right)\end{array}$ & $\begin{array}{l}\max \_a w v c \\
\left(\mathrm{~kg} / \mathrm{m}^{2}\right)\end{array}$ & $\begin{array}{l}\text { Month of } \\
\min / \max \end{array}$ & $\begin{array}{l}\min \_a w v c \\
\left(\mathrm{~kg} / \mathrm{m}^{2}\right)\end{array}$ & $\begin{array}{l}\max \_a w v c \\
\left(\mathrm{~kg} / \mathrm{m}^{2}\right)\end{array}$ & $\begin{array}{l}\text { Month } \\
\text { of } \min / \max \end{array}$ \\
\hline \multicolumn{7}{|l|}{$N E$} \\
\hline Yola & 15.79371 & 49.501008 & Jan/Aug & 14.909 & 46.18111 & Jan/Aug \\
\hline Bauchi & 13.52839 & 47.185048 & Jan/Aug & 13.7471 & 45.72493 & Jan/Aug \\
\hline Maiduguri & 12.52404 & 48.872285 & Jan/Aug & 12.8954 & 47.29769 & Jan/Aug \\
\hline Gombe & 14.29329 & 49.449674 & Jan/Aug & 13.7503 & 46.37705 & Jan/Aug \\
\hline Jalingo & 19.36956 & 49.630523 & Jan/Aug & 18.8927 & 46.40984 & Jan/Aug \\
\hline Damaturu & 12.15162 & 48.501179 & Jan/Aug & 12.3187 & 45.82939 & Jan/Aug \\
\hline \multicolumn{7}{|l|}{$N W$} \\
\hline Dutse & 12.43383 & 48.042188 & Jan/Aug & 12.5883 & 44.60418 & Jan/Aug \\
\hline Kano & 12.81454 & 46.106445 & Jan/Aug & 13.5029 & 45.21072 & Jan/Aug \\
\hline Katsina & 12.59129 & 46.009284 & Jan/Aug & 13.4438 & 44.94065 & Jan/Aug \\
\hline Kaduna & 15.35333 & 45.220784 & Jan/Aug & 16.5884 & 46.62931 & Jan/Aug \\
\hline Birnin Kebbi & 14.81469 & 50.889957 & Jan/Aug & 16.6766 & 48.81523 & Jan/Aug \\
\hline Sokoto & 12.93422 & 48.894296 & Jan/Aug & 13.9721 & 46.88473 & Jan/Aug \\
\hline Gusau & 13.62224 & 47.856184 & Jan/Aug & 14.7881 & 46.80198 & Jan/Aug \\
\hline \multicolumn{7}{|l|}{$N C$} \\
\hline Lokoja & 27.56792 & 51.812972 & Jan/Sept & 27.818 & 53.25388 & Jan/Aug \\
\hline Ilorin & 21.65518 & 50.377122 & Jan/Aug & 25.441 & 52.48986 & Jan/Aug \\
\hline Lafia & 22.19727 & 50.69544 & Jan/Aug & 21.9241 & 49.43433 & Jan/Aug \\
\hline Minna & 19.26518 & 52.15308 & Jan/Aug & 20.6612 & 49.83704 & Jan/Aug \\
\hline Jos & 16.71646 & 47.400446 & Jan/Aug & 17.3361 & 47.13338 & Jan/Aug \\
\hline Makurdi & 25.63675 & 53.13367 & Jan/Aug & 25.367 & 50.71285 & Jan/Aug \\
\hline Abuja & 22.89216 & 51.23266 & Jan/Aug & 22.5155 & 50.23443 & Jan/Aug \\
\hline \multicolumn{7}{|l|}{ SW } \\
\hline Ikeja & 36.56653 & 54.762395 & Jan/May & 34.9707 & 55.08442 & Jan/Aug \\
\hline Abeokuta & 34.4337 & 53.595811 & Jan/May & 33.5317 & 54.98046 & Jan/Aug \\
\hline Akure & 33.19473 & 52.77265 & Jan/May & 32.9027 & 54.84997 & Jan/Aug \\
\hline Oshogbo & 29.91348 & 50.422181 & Jan/May & 31.2428 & 54.79889 & Jan/Aug \\
\hline Ibadan & 26.73888 & 50.029051 & Jan/Sept & 29.1986 & 54.03758 & Jan/Aug \\
\hline Ado Ekiti & 27.92469 & 49.620901 & Jan/May & 29.887 & 54.26263 & Jan/Aug \\
\hline \multicolumn{7}{|l|}{ SS } \\
\hline Port Harcourt & 40.14725 & 55.643176 & Jan/May & 38.0813 & 53.9562 & Jan/Aug \\
\hline Calabar & 31.36698 & 52.290557 & Jan/May & 31.2958 & 50.42125 & Jan/Aug \\
\hline Uyo & 39.78896 & 55.561116 & Jan/May & 36.7228 & 52.79754 & Jan/Aug \\
\hline Asaba & 37.92639 & 56.235149 & Jan/May & 36.16 & 54.62572 & Jan/Aug \\
\hline Yenagoa & 41.27125 & 56.299205 & Jan/May & 38.9496 & 54.49096 & Jan/Aug \\
\hline Benin City & 33.5298 & 53.834741 & Jan/May & 33.1672 & 54.44351 & Jan/Aug \\
\hline \multicolumn{7}{|l|}{$S E$} \\
\hline Umuahia & 36.71783 & 55.304448 & Jan/May & 35.5246 & 53.5983 & Jan/Aug \\
\hline Awka & 33.65775 & 54.818835 & Jan/May & 33.4111 & 53.82795 & Jan/Aug \\
\hline Enugu & 31.49726 & 54.287204 & Jan/May & 31.4186 & 53.392 & Jan/Aug \\
\hline Abakaliki & 31.72115 & 54.669602 & Jan/May & 31.1218 & 51.96945 & Jan/Aug \\
\hline Owerri & 36.66827 & 55.332726 & Jan/May & 35.747 & 53.91827 & Jan/Aug \\
\hline
\end{tabular}

$N E$ north-east, NW north-west, NC north-central, SW south-west, SE south-east, SS south-south 
Table 3 Zonal average of the minimum and maximum monthly mean values of AWVC over Nigeria

\begin{tabular}{|c|c|c|c|c|c|c|}
\hline \multirow[t]{2}{*}{ Zone } & \multicolumn{3}{|c|}{$\begin{array}{l}\text { ERA-I } \\
\text { [Zonal Mean }\left(\mathrm{kg} / \mathrm{m}^{2}\right)\end{array}$} & \multicolumn{3}{|c|}{$\begin{array}{l}\text { NCEP/NCAR } \\
{\left[\text { Zonal Mean }\left(\mathrm{kg} / \mathrm{m}^{2}\right)\right]}\end{array}$} \\
\hline & min_wv & max_wv & Month & min_wv & max_wv & Month \\
\hline NW & 13.50920 & 47.57420 & Jan/Aug & 14.50860 & 46.26950 & Jan/Aug \\
\hline NE & 14.61010 & 48.85660 & Jan/Aug & 14.41890 & 46.30330 & Jan/Aug \\
\hline $\mathrm{NC}$ & 22.27590 & 50.97220 & Jan/Aug & 23.00899 & 50.44225 & Jan/Aug \\
\hline SW & 31.46200 & 51.86716 & Jan/May & 31.95558 & 54.66899 & Jan/Aug \\
\hline SE & 34.05245 & 54.88256 & Jan/May & 33.44462 & 53.34119 & Jan/Aug \\
\hline SS & 37.33844 & 54.97732 & Jan/May & 35.72945 & 53.45586 & Jan/Aug \\
\hline
\end{tabular}

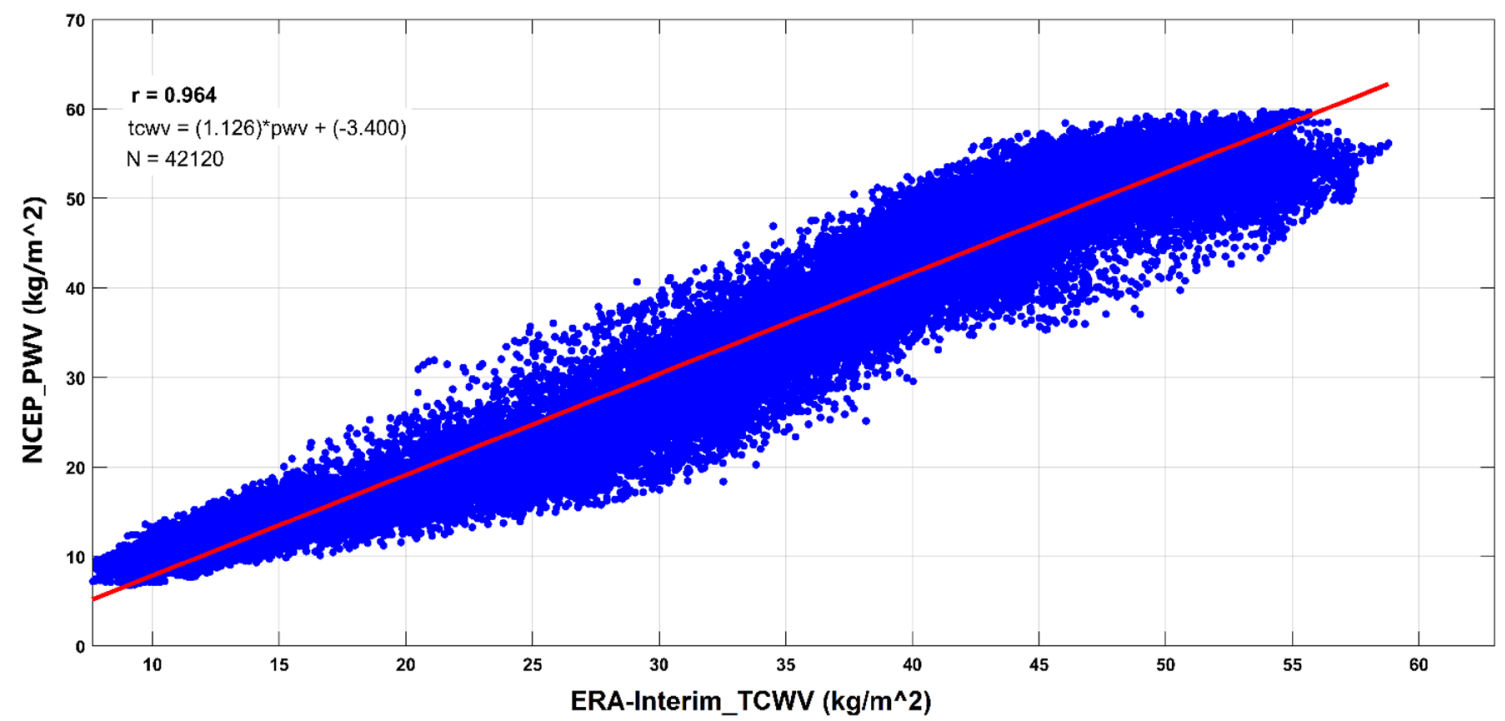

Fig. 10 Regression between the NCEP/NCAR and ERA-I AWVC over Nigeria (2007-2017)

Table 4 Summary of the result of the statistical performance index of the data sets

\begin{tabular}{lc}
\hline Metric (statistical criteria) & Estimated value \\
\hline Root-mean-squared error (RMSE) & 4.239214 \\
Mean absolute error (MAE) & 3.419586 \\
Mean absolute relative error (MARE) & 0.102058 \\
Coefficient of correlation $(r)$ & 0.963705 \\
Coefficient of determination $\left(R^{2}\right)$ & 0.928727 \\
Coefficient of efficiency $(E)$ & 0.878309 \\
Maximum absolute error & 14.17145 \\
Maximum absolute relative error & 0.518598 \\
\hline
\end{tabular}

The coefficient of efficiency $(E)$ of about $87.8 \%$ shows high level of internal efficiency of the predicted (ERA-I) and observed data (NCEP/NCAR). Therefore, Eqs. (12) and (13) are sufficient for the estimation of AWVC over the study area, giving either of the two as input variable.

\subsection{Discussions}

Figures 4 and 5 show that atmospheric water vapour contents vary spatially and are location dependent. Therefore, the choice of investigating the monthly mean for 37 stations, representing all states capital in Nigeria, including the Federal Capital Territory (FCT) is very relevant and appropriate. The analysis of monthly means of atmospheric water vapour for the selected locations showed that May-September of 2007-2017 represents the period with highest values of AWVC over Nigeria. On the other hand, November-February represents the period with lowest values of atmospheric water vapour contents over Nigeria. Relatively, the two periods are the expected peak wet and dry seasons in the study area, and this corroborates observations by [3], [45], [36], [27] and [49], respectively.

Figures $6 a, b$ and Table 2 , show that the locations in the southern region of Nigeria (SS, SW and SE) have AWVC at lowest and highest in the months of January and May, respectively, for the period of 2007-2017, while the locations in the northern Nigeria (NW, NE and NC) had their 
lowest and highest monthly mean of AWVC mainly in the months of January and August, respectively. By comparison, all regions in Nigeria exhibited minimum and maximum values of AWVC in January and August, respectively, with the NCEP data, while the ERA-I data set showed a bimodal patterns of minimum and maximum values in January/August for the Northern region, and January/May for the southern region of the country, respectively. The bimodal patterns of the ERA-I data set are attributable to two factors. The first is that the data sampling resolution of $0.75^{\circ} \times 0.75^{\circ}$ has the higher probability of revealing disparity in microvariations across the study area, where they do exist than the NCEP data set with $2.5^{\circ} \times 2.5^{\circ}$ resolution. The second factor is that the southern region of Nigeria practically exhibits slightly different atmospheric water vapour regime from that of the Northern region. This is an indication that the values and timings of precipitation pattern in the southern and northern regions of Nigeria may vary. For instance, over the years in the southern region, light rainfall set in during the month of March and reached its peak between May and July, while in the northern region, the rains set in by the month of May and reached its peak by September. Therefore, these maximum values of AWVC recorded in the month of May for the southern region indicate a peak of occurrence of precipitable water vapour over the area under the period of investigation. This information is important for rainfall prediction, and radio signal transmission and measurements within the period over the southern region of Nigeria.

Figures 7 and 8 show the average monthly mean of variations of AWVC $\left(\mathrm{kg} / \mathrm{m}^{2}\right)$ for the entire period of 2007-2017 and the latitudinal variations (north-south variations) of AWVC over Nigeria. These figures present a general outlook of the climatology of water vapour regime over Nigeria during the entire period of study and perhaps indicate the probable peak periods for the wet and dry seasons in the study area. Due to the high spatial variability of atmospheric water vapour contents, a single map of average monthly mean of atmospheric water vapour contents (AWVC) for the entire study area will be overgeneralised and misleading and may not be suitable for further analysis. This is because it would have substantially reduced or increased the water vapour values from the extreme high and low values, which makes them less representative and accurate when compared to daily/monthly mean of selected locations across the country. The choice of 37 capital city locations in Nigeria including the Federal Capital Territory (FCT) for the analysis was predicted on this fact. Therefore, Figs. 7 and 8 suffice as data/seasonal visualisation tool. Figure 8 in particular reveals the latitudinal variations in AWVC in which the values increase with decreasing latitudes from the north towards the coast of Nigeria. This is validated by Fig. 9 which shows locations in the lower latitude recording higher values of AWVC than the northern counterpart all through the years.

From the NCEP/NCAR data analysis, all the 37 sampled cities in the study had their lowest and highest monthly mean AWVC in the months of January and August, which indicates the peak of the dry and wet seasons for the period of 2007-2017. On the other hand, the ERA-I showed some variations in the peak periods across the six geopolitical zones of Nigeria. The NW cities of Dutse, Kano, Katsina, Kaduna, Birnin Kebbi, Gusau and Sokoto had their lowest and highest monthly mean of atmospheric water vapour contents similar to those of the NE. Dutse and Katsina are having the least AWVC in both ERA-I and NCEP/NCAR data sets.

In the NE cities of Yola, Maiduguri, Bauchi, Damaturu, Jalingo and Gombe, the lowest and highest monthly mean AWVCs were in the months of January and August, respectively, for the years 2007-2017, with Damaturu having the least ERA-I and NCEP/NCAR AWVC values amongst the NE cities. A general decreasing trend in rainfall amounts from the southern parts of Kaduna and Bauchi to the northern parts of Nguru, Maiduguri and Sokoto, and environs within the period of 2007 and 2019 were observed and predicted by [2]. Also, the estimated trend of AWVC in these locations and their environs further affirms the observations by [2]. A general decreasing trend in rainfall amounts from the southern parts of Kaduna and Bauchi to the northern parts of Nguru, Maiduguri and Sokoto, and environs within the period of 2007 and 2019 were observed and predicted by [2], and the estimated trend of AWVC at those locations and their environs by this study further affirmed the observations.

With ERA-I, the NC cities of Ilorin, Lafia, Minna, Makurdi, Jos and Abuja had their respective lowest and highest monthly mean of AWVC in the months of January and August, respectively, while Lokoja had its lowest and highest monthly mean of AWVC in January and September, respectively, which is similar only to Ibadan in the SW zone. Within the NC zone, Jos had the least mean monthly values of ERA-I and NCEP/NCAR AWVC. The Guinean Highlands and the Jos Plateau in central Nigeria are known to receive more precipitation than lowlands of the same latitude due to altitudes [2,32], but this study, however, showed Jos, on the Plateau recording the lowest monthly average AWVC amongst all other locations in the northcentral zone of Nigeria AWVC from both ERA-I and NCEP/ NCAR, respectively.

The SW cities of Abeokuta, Ikeja, Akure, Ado-Ekiti and Oshogbo had their lowest and highest monthly mean of AWVC in the months of January and May, respectively. Ibadan had the least monthly mean values in both the ERA-I and NCEP/NCAR analysis. The lowest and highest monthly mean of the ERA-I AWVC in the SS cities of Port 
Harcourt, Calabar, Uyo, Asaba, Yenagoa and Benin City was recorded in the months of January and May, respectively, with Calabar recording the least values with ERA-I and NCEP/NCAR in the zone. The SE trend is similar to that of SS, with Abakaliki having the least ERA-I and NCEP/NCAR AWVC in the zone.

On the general average, ERA-I water vapour data analysis over Nigeria showed a north-south dichotomy, with the cities in the southern region of Nigeria (SS, SW and SE) having AWVC at lowest and highest in the months of January and May, respectively, for the period of 2007-2017. On the other hand, the cities in the northern Nigeria (NW, NE and NC) had their lowest and highest monthly mean of AWVC in both ERA-I and NCEP/NCAR data analysis, mainly in the months of January and August, respectively [see Figs. 6a, b,9a, b and Tables 2, 3]. These estimated differences in the water vapour contents between the northern and the southern parts of Nigeria corroborate the pattern of precipitation climatologies of Nigeria reported by [3] and [4], which showed that the precipitation climatologies of the northern and southern parts of Nigeria differ appreciably; which corroborates reports by [3], [5] and [63] that Nigeria becomes progressively drier as one moves northward from the coast of Nigeria.

Figure 10 shows the linear regression of the ERA-I and NCEP/NCAR data sets. The total data sample $(N)$ was 42120 , and the linear relationship between the ERA-I and NCEP/ NCAR data sets is given by Eqs. (12) and (13), respectively. With Eq. 12, given the grid values of NCEP AWVC data, the ERA-I estimate can be realised, and vice versa. Table 4 contains the computed error measures as the data metric performance index. The estimates include coefficient of correlation of about $96.37 \%$, coefficient of determination $\left(R^{2}\right)$ of about $92.9 \%$ and a coefficient of efficiency of $87.83 \%$, and others. The values indicate that ERA-I and NCEP/NCAR data sets have close grid values, and the relationship between them in estimating AWVC over any selected location is statistically significant and valid. The coefficient of efficiency (E) of about $87.8 \%$ shows high level of internal efficiency of the ERA-I and NCEP/NCAR data sets used in this study.
Table 5 presents the best line of fit from polynomial models for each of the six geo-political zones of Nigeria. For ERA-I, a range of the $R^{2}$ results for the best line-of-fit determination was $78.36-95.75 \%$, and for NCEP/NCAR a range of $R^{2}$ results for the best line-of-fit determination was $81.24-94.13 \%$.

\subsection{Implications of the water vapour regime over Nigeria}

The accurate knowledge of water vapour contents, patterns, spatial and temporal variability is indispensable for the investigation and description of regional weather and climate processes, wet refractivity of water vapour analysis over spatial locations and positioning for precise navigation and mapping and estimation of attenuation constants of radio waves propagation of satellite signals over selected communication antennae or geodetic observatory, etc.

The southern parts of Nigeria have shown consistently high AWVC in this study, and this implies high $\mathrm{RH}$ over the area. According to Al-Saegh [8], the regions near the sea and the equator usually suffer from higher $\mathrm{RH}$ which indicates increased gases attenuation. Satellite signals would continually be predisposed to poor reception in the south due to the effects of absorption, refraction, attenuations, scintillations, diffraction, fading, multipath, amongst others, due to vapour contents lining across the atmospheric layers; hence, there may be a need for network and signal modulation and argumentation systems across the region. For satellite television and radio communication, the Ku-band will be a major victim. However, clearer satellite signals and higher performance atmospheric window with minimal clutters are likely in the northern region of Nigeria.

The water vapour contents are expectedly lower in the higher latitudes of Northern Nigeria than the lower latitudes of Southern region, which potentially supports more precipitations or rains in the south than in the north. This, however, has been the regime over the years in Nigeria.

Table 5 Polynomial trend fitting models for some cities in the geopolitical zones of Nigeria

\begin{tabular}{|c|c|c|c|c|}
\hline \multirow[t]{2}{*}{ City/zone } & Model & $R^{2}$ & Model & $R^{2}$ \\
\hline & \multicolumn{2}{|l|}{ ERA-I } & \multicolumn{2}{|l|}{ NCEP/NCAR } \\
\hline Damaturu (NE) & $y=-1.0852 x^{2}+15.064 x-11.67$ & 0.7836 & $y=-0.9649 x^{2}+13.621 x-9.3235$ & 0.8124 \\
\hline Oshogbo (SW) & $y=-0.6763 x^{2}+9.0096 x+21.937$ & 0.9445 & $y=-0.6056 x^{2}+8.5215 x+20.865$ & 0.8951 \\
\hline Lafia (NC) & $y=-0.9856 x^{2}+13.248 x+7.2087$ & 0.9575 & $y=-0.7752 x^{2}+10.826 x+8.6152$ & 0.9413 \\
\hline Birnin Kebbi (NW) & $y=-1.2211 x^{2}+16.794 x-9.9597$ & 0.8695 & $y=-0.9349 x^{2}+13.056 x-1.3104$ & 0.91 \\
\hline Enugu (SE) & $y=-0.7354 x^{2}+9.8735 x+22.592$ & 0.9359 & $y=-0.5809 x^{2}+8.2556 x+21.487$ & 0.9273 \\
\hline $\mathrm{P} / \mathrm{H}(\mathrm{SS})$ & $y=-0.6763 x^{2}+9.0096 x+21.937$ & 0.9445 & $y=-0.4121 x^{2}+6.0249 x+30.572$ & 0.9327 \\
\hline
\end{tabular}

$y\left(\mathrm{~kg} / \mathrm{m}^{2}\right)$ represents the vapour value and $x$ represents the period/month 
The general spatial trend can best be explained by polynomial or moving average models, but there are no evidences of sustained decrease or increase of vapour values or pattern over an area with respect to the temporal resolution. In other words, the water vapour values over a station from previous years or months may be higher or lower than the present and vice versa.

Also, the climate change impact of the sustained high content of atmospheric water vapour in the south is a potential increase in temperature and flooding in the region, while in the north, the usual low-average precipitation may prevail and further exacerbate drought and dryness. It was observed by [5] that air temperature values are generally lower in the northern part of Nigeria during dry season when compared with the wet season, while [1] observed that the amount of water vapour in the air is small in extremely arid areas and in location where the temperatures are very low. Therefore, inferences from these literatures, combined with the AWVC variability and trend obtained in this study, have shown that low atmospheric water vapour contents go with low air temperature and low precipitation during the dry season in the northern part of Nigeria and vice versa in the wet season. Also, the estimated atmospheric water vapour contents over the southern region of Nigeria were averagely high, implying corresponding high air temperature and high precipitation when compared to the northern part.

\section{Conclusions}

The study investigated the spatial variability of the atmospheric water vapour contents (AWVC) over 37 capital city locations in Nigeria using the European Centre for Medium-Range Weather Forecasts (ECMWF) ERA-Interim (ERA-I) and National Centres for Environmental Prediction/ National Centre for Atmospheric Research (NCEP/NCAR) reanalysis data for the period of 2007-2017. The study confirmed the spatial heterogeneity of AWVC over Nigeria, which showed decrease in atmospheric water vapour from south to north and vice versa. The Jos Plateau region in central Nigeria known to receives more precipitation than lowlands of the same latitude due to altitudes showed the lowest monthly average AWVC amongst all other locations in the north-central zone of Nigeria from both ERA-I and NCEP/NCAR data analysis for 2007-2017.

The AWVC regime over the stations in the southern region of Nigeria (SS, SW and SE) exhibited bimodal patterns with the ERA-I data, recording lowest and highest values in the months of January and May, respectively, while the stations in the northern region (NW, NE and NC) recorded their lowest and highest monthly mean of AWVC in the months of January and August, respectively for the period of study. The NCEP data set, however, showed unimodal patterns of lowest and highest monthly mean of AWVC in the months of January and August for all stations across the country. It is therefore important to note that the bimodal patterns of AWCV exhibited by stations with the ERA-I data set are attributable to two factors. The first is the higher spatial data sampling resolution of $0.75^{\circ} \times$ $0.75^{\circ}$ of ERA-I as against the $2.5^{\circ} \times 2.5^{\circ}$ resolution of the NCEP, while the second is the slightly different AWVC and wetness regime in the southern region from that of the northern region of Nigeria. This shows that the values and timings of precipitation pattern between the southern and northern regions of Nigeria may vary from time to time.

The overall analysis of the climatology of the monthly means of atmospheric water vapour for selected locations across Nigeria showed that May-September of 2007-2017 represents the period with highest values of AWVC over Nigeria. The implication of this is that satellite signal attenuations due to the presence of water vapour will be highest within the period. On the other hand, November-February represents the period with lowest values of atmospheric water vapour contents over Nigeria, which is expected to be a period of less signal attenuation across Nigeria. The periods could be classified as the peak wet and dry seasons, respectively, for the study area.

The average zonal analysis indicates that Damaturu (NE), Dutse/Katsina (NW), Jos (NC), Ibadan (SW), Abakaliki (SE) and Calabar (SS) have the least monthly mean AWVC values in both the ERA-I and NCEP/NCAR analyses. By comparison, the NW had the least average AWVC within the period of study, followed by NE, NC, SW, SE and SS in that order. In summary, the records of respective minimum and maximum AWVC over nearly all the 37 state capital cities in Nigeria between 2007 and 2017 in the months of January and August, respectively, in this study confirm the peak of dry and wet seasons.

The models and spatial maps of AWVC produced from both ERA-I and NCEP/NCAR data sets in this study are recommended for use for the empirical estimation of AWVC and validations of other independent water vapour retrieval solutions such as global navigation satellite system (GNSS) and aerospace radiometry over the study area. However, it has been observed by other studies that ERA-I had some uncertainties in some regions such as the Antarctica and North Africa. West Africa is, however, not amongst the regions of ERA-I uncertainties; hence, it provides a viable source of filling GPS/GNSS integrated water vapour data gaps or breaks in data collection, and stations discontinuities or nonexistence in Nigeria and other parts of West Africa for relevant applications. Based on the better spatial resolutions of ERA-I data set and the results as compared to NCEP/NCAR data set in this study, the ERA-I is recommended to be used as the first priority data set for 
investigating AWVC over the study area. Alternatively, the ERA5 HRES data covering the period from 1979 and with high spatial resolution of about $31 \mathrm{~km}$ are recommended for GNSS high-density network-based vapour retrieval validations and climatological studies over Nigeria.

Acknowledgements Thanks to the European Centre for MediumRange Weather Forecasts (ECMWF) and National Centers for Environmental Prediction, National Oceanic and Atmospheric Administration (NCEP-NOAA) for providing the reanalysis data for the study. Special thanks to Robert B. Schmunk of NASA Goddard Institute for Space Studies, NY, USA, for developing and providing open access to Panoply 4.8.6., which was used for reading the NetCDF data in this study. Thanks to MathWorks for enormous computational, modelling and graphic resources in the MATLAB software series.

\section{Compliance with ethical standards}

Conflict of interest The authors hereby state that there is no conflict of interest with any party during the research and in the preparation of the manuscript.

\section{References}

1. Adam D (2010) Climate change. Environ Corresp. https://www. theguardian.com/environment/2010/jan/29/water-vapou r-climate-change

2. Adakayi PE (2012) An assessment of the rainfall and temperature variations in parts of Northern Nigeria. Thesis for the Degree of Doctor of Philosophy in Environmental Resources Planning of the University of Jos, Nigeria

3. Adeyemi B, Ogolo EO (2014) Diurnal and seasonal variations of surface water vapour density over some meteorological stations in Nigeria. Ife J Science 16(2):181-189

4. Adeyemi B, Joerg S (2012) Analysis of water vapour over Nigeria using radiosonde and satellite data. J Appl Meteorol Climatol 51:1855-1866

5. Akinsanola AA, Ogunjobi KO (2014) Analysis of rainfall and temperature variability over Nigeria. Glob J Hum Soc Sci XIV(III). Version Online ISSN: 2249-460x \& Print ISSN: 0975-587X. 1

6. Akinwumi SA, Omotosho TV, Usikalu MR, Ometan OO, Adewusi MO, Adagunodo TA (2018) Study of oxygen and water vapour attenuation in West Africa. Interciencia J 43(1):180-191. ISSN: 0378-1844

7. Akinwumi SA, Omotosho TV, Usikalu MR, Adewusi MO, Ometan OO (2016) Atmospheric gases attenuation in West Africa. In: 2016 IEEE Radio and Antenna Days of the Indian Ocean (RADIO). https://doi.org/10.1109/radio.2016.7772040

8. Al-Saegh MA, Sali A, Mandeep JS, Ismail A, Al-Jumaily AHJ, Gomes C (2014) Atmospheric propagation model for satellite communications. Chapter 9. InTech Open Science, pp 249-275. http://dx.doi.org/10.5772/58238

9. Amina MD (2013) Climate change is threat to Nigeria's Vision 20:2020-World Bank Publ. June 10

10. Andersson E et al (2007) Analysis and forecast impact of the main humidity observing systems. Q J Roy Meteorol Soc 133:1473-1485

11. Ana Claudia Bernardes Parracho (2018). Study of trends and variability of atmospheric water vapour with climate models and observations from global GNSS Network. Climatology. Université
Pierre et Marie Curie - Paris VI. https://tel.archives-ouvertes.fr/ tel-01881083/document. Accessed on 9th July 2019

12. Arfaoui M, Inoubli HM (2013) Advantages of using the kriging interpolator to estimate the gravity surface, comparison and spatial variability of gravity data in the El Kef-Ouargha region (northern Tunisia). Arab J Geosci 6:3139-3147. https://doi. org/10.1007/s12517-012-0549-y

13. Berrisford $P$, Dee D, Poli P, Brugge R, Fielding K, Fuentes M, Kallberg P, Kobayashi S, Uppala S, Simmons A (2011) ERA Report Series No. 1 version 2.0. ERA-Interim Archive. ECMWF, Shinfield Park, Reading, Berkshire RG2 9AX, United Kingdom October. http://www.ecmwf.int/publications/

14. Berrisford $P$, Dee $D$, Fielding $K$, Fuentes $M$, Kallberg $P$, Kobayashi S, Uppala SM (2009) ERA Report Series No. 1, Version 1.0. The ERA-Interim Archive. ECMWF, Shinfield Park, Reading, Berkshire RG2 9AX, United Kingdom. http://www.ecmwf.int/publications/

15. Bevis M, Businger S, Herring T, Rocken C, Anthes R, Wave R (1992) GPS meteorology: remote sensing of atmospheric water vapor using the global positioning system. J Geophys Res 97:787-801. https://doi.org/10.1029/92JD01517

16. Chaboureau J-P, Chédin A, Scott NA (1998) Remote sensing of the vertical distribution of atmospheric water vapour from the TOVS observations. Method and validation. J Geophys Res 103:8743-8752

17. Cressie N (1990) The origins of kriging. Math Geol 22:239-252. https://doi.org/10.1007/BF00889887

18. Despotovic M, Nedic V, Despotovic D, Cvetanovic S (2016) Evaluation of empirical models for predicting monthly mean horizontal diffuse solar radiation. Renewable and Sustainable Energy Reviews 56:246-260. https://doi.org/10.1016/j.rser.2015.11.058

19. Divakarla MG, Barnet CD, Goldberg MD, McMillin LM, Maddy E, Wolf W, Zhou L, Liu X (2006) Validation of Atmospheric Infrared Sounder temperature and water vapour retrievals with matched radiosonde measurements and forecasts. J. Geophys. Res. 111:D09S15. https://doi.org/10.1029/2005jd006116

20. Deeter MN (2007) A new satellite retrieval method for precipitable water vapour over land and ocean. Geophys Res Lett 34:L02815. https://doi.org/10.1029/2006GL028019

21. Dee DP, Uppala SM, Simmons AJ, Berrisford P, Poli P, Kobayashi $S$, Andrae U, Balmaseda MA, Balsamo G, Bauer P, Bechtold $P$, Beljaars ACM, van de Berg L, Bidlot J, Bormann N, Delsol C, Dragani R, Fuentes M, Geer AJ, Haimberger L, Healy SB, Hersbach H, Hólm EV EV, Isaksen L, Kållberg P, Köhler M, Matricardi M, McNally AP, Monge-Sanz BM, Morcrette J-J, Park B-K, Peubey C, de Rosnay P, Tavolato C, Thépaut J-N, Vitart F (2011) The ERAInterim reanalysis: configuration and performance of the data assimilation system. Q J R Meteorol Soc 137:553-597. https:// doi.org/10.1002/qj.828

22. Elgered G (1993) Tropospheric radio path delay from groundbased microwave radiometry. Atmospheric remote sensing by microwave radiometry. Wiley, New York, pp 215-258

23. ESRI Digital ArcGlobe Data. ArcMap Software. www.esri.com

24. Gerard J (2018) How to calculate mean absolute error. https:// sciencing.com/calculate-mean-absolute-error-6426845.html. Accessed on 26th April 2019

25. Gutman $\mathrm{SI}$ (n.d) Tropospheric modelling. Observing system section, NOAA Earth System Research Lab. Boulder, Colorado, USA. Ppt. Published by Simon Ferguson https://slideplayer.com/slide /7408835/. Accessed on 20 May 2019

26. Haby J (n.d) Atmospheric water vapour. http://www.theweather prediction.com/habyhints/40/. Accessed on 20 Nov 2018

27. Hastenrath S (1991) Climate dynamics of the tropics. Kluwer, Dorddrecht, $p 488$

28. Held IM, Soden BJ (2000) Water vapour feedback and global warming. Annu Rev Energy Environ 25:441-475 
29. Heinkelmann R, Schmidt M, Böhm J, Schuh H (2007) Determination of water vapor trends from VLBI observations. Österreich Zeit Vermess Geoinf 95(73-79):2007

30. Hum VS (2015) Atmospheric effects, attenuation by atmospheric gases. Radio Microw Wireless Syst. www.academicscience.co.in/ admin/resources/project/.../f201509241443097241.pdf

31. https://psa.gov.ph/content/coefficient-efficiency

32. https://eros.usgs.gov/westafrica/node/157. Mean annual rainfall 1981-2014, with number of months of $50 \mathrm{~mm}$ or more of rainfall. Accessed on 19 May 2019

33. IEEE (1991) 211-1990 - IEEE Standard Definitions of Terms for Radio Wave Propagation. Electronic ISBN: 0-7381-4351-0. https ://ieeexplore.ieee.org/document/159314/definitions

34. Institute of Business Forecasting \& Planning (IBF) (2019) MAPE: mean absolute percentage error. https://ibf.org/knowledge/ glossary/mape-mean-absolute-percentage-error-174. Accessed on 26 Apr 2019

35. Jackson DL, Stephens GL (1995) A study of SSM/I-derived Columner water vapour over the global Oceans. J Clim 8:2025-2038

36. Jegede OO, Mauder M, Okogbue EC, Foken T, Balogun EE, Adedokun JA, Oladiran EO, Omotosho JA, Balogun AA, Oladosu OR, Sunmonu LA, Ayoola MA, Aregbesola TO, Ogolo EO, Nymphas EF, Adeniyi MO, Olutona GI, Ladipo KO, Ohamobi SI, Gbobaniyi EO, Akinlade GO (2004) The Nigerian micrometeorological experimental (NIMEX) overview. Ife J Sci 6(2):191-202

37. Kanamitsu M et al (1991) Recent changes implemented into the Global Forecast System at NMC. Weather Forecast 6:425-435

38. Karbou F, Aires F, Prigent C, Eymard L (2005) Potential of advanced microwave sounding unit-A (AMSU-A) and AMSU$B$ measurements for atmospheric temperature and humidity profiling over land. J Geophys Res 110:D07109. https://doi. org/10.1029/2004JD005318

39. Kistler R et al (2001) The NCEP-NCAR 50-year reanalysis: monthly means CD-ROM and documentation. Bull Am Meteorol Soc 82:247-267

40. Miao J, Kunzi K, Heygster G, Lachlan-Cope TA, Turner J (2001) Atmospheric water vapour over Antarctica derived from Special Sensor Microwave/Temperature 2 data. J Geophys Res 106:10187-10203

41. Murphy AH (1988) Skill Scores based on the mean square error and their relationship to the correlation coefficient. Mon Weather Rev 116:2417-2424

42. Mahmoudabadi $H$, Briggs $G$ (2016) Directional kriging implementation for gridded data interpolation and comparative study with common methods. NASA Astrophysics Data System (ADS). https://www.science.gov/topicpages/k/kriging+inter polation+method

43. Nicholson SE, Dezfuli AK (2013) The relationship of rainfall variability in western equatorial africa to the tropical oceans and atmospheric circulation. Part I: The Boreal Spring. J Clim Am Meterol Soc. https://doi.org/10.1175/jcli-d-11-00653.1

44. Ning T, Wang J, Elgered G, Dick G, Wickert J, Bradke M, Sommer M, Querel R, Smale D (2016) The uncertainty of the atmospheric integrated water vapour estimated from GNSS observations. Atmos Meas Tech 9:79-92. https://doi.org/10.5194/ amt-9-79-2016

45. Ogolo EO, Falodun SE (2007) Variations and trends in long term annual mean air temperatures over some selected cities in Nigeria. J Phys Sci 3(2):40-44

46. Ojigi ML (2011) Determination of suitable terrain surface modeling algorithms for hydraulics design of storm sewer. In: Fajemirokun FA (ed) Contemporary issues in surveying \& geoinformatics. Published by BPrint, Ikeja, Nigeria, pp 103-133. ISBN 97 8-915-670-2

47. Ojo O (1977) The climate of West Africa. Heineman, London
48. Olalekan I, Ludwig C, Ondego B (2017) Retrieval and analysis of precipitable water vapour based on GNSS, AIRS, and reanalysis models over Nigeria. Int J Remote Sens 38:5710-5735. https:// doi.org/10.1080/01431161.2017.1346401

49. Olaniran OJ, Sumner GN (1989) A study of climatic variability in Nigeria based on the onset, retreat, and length of the rainy season. Int J Climatol 9:253-269

50. Paraboni A, D'Amico M, Capsoni C, Riva CG, Luini L (2018) Effects of the atmosphere on radiowave propagation. Appl Electromagn Space Commun Remote Sens

51. Pokam WM, Djiotang LAT, Mkankam FK (2012) Atmospheric water vapor transport and recycling in Equatorial Central Africa through NCEP/NCAR reanalysis data. Climate Dynamics 38(9-10):1715-1729. https://doi.org/10.1007/s0038 2-011-1242-7

52. Quest (2014)Water vapour's role in climate change. Environment. https://ww2.kqed.org/quest/2014/12/12/water-vapou rs-role-in-climate-change/

53. Randel LD, Vonder Haar HT, Ringerud AM, Stephens LG, Greenwald JT, Combs LC (1996) A new global water vapour dataset. Bull Am Meterol Soc 77(6):1233-1246

54. Ross RJ, Elliott WP (1996) Tropospheric water vapour climatology and trends over north America: 1973-93. J Clim 9:3561-3574. https://doi.org/10.1175/15200442(1996)009\%3c3561:TWVCA T\%3e2.0.CO;2

55. Rossow WB, Garder CL, Lu JP, Walker WA (1991) International Satellite Cloud Climatology Project (ISCCP) documentation of cloud data. WMO/TD-No, 266, World Meteorological Organisation

56. Schmetz J, Menzel PW, Veldon C, Wu X, van de Berg L, Nieman S, Hayden C, Holmlund K, Geijo C (1995) Monthly mean largescale analyses of upper troposphere humidity and wind field divergence derived from three geostationary satellites. Bull Am Meterol Soc 76:1578-1584

57. Schröder $M$, Lockhoff $M$, Fell F, Forsythe J, Trent $T$, Bennartz R, Borbas E, Bosilovich GM, Castelli E, Hersbach H, Kachi M, Shinya Kobayashi S, Kursinski ER, Loyola D, Mears C, Preusker R, Rossow BW, Saha S (2018) The GEWEX water vapour assessment archive of water vapour products from satellite observations and reanalyses. Earth Syst. Sci. Data 10:1093-1117. https://doi. org/10.5194/essd-10-1093-2018 (Distributed under the Creative Commons Attribution 4.0 License)

58. Shcherbakov MV, Brebels A, Shcherbakova NL, Tyukov AP, Janovsky TA, Kamaev VA (2013) A survey of forecast error measures. World Appl Sci J 24:171-176. https://doi.org/10.5829/idosi .wasj.2013.24.jtimes.80032

59. Solheim FS, Vivekanandan J, Ware RH, Rocken C (1999) Propagation delays induced in GPS signals by dry air, water vapor, hydrometeors, and other particulates. J Geophys Res 104(D8):9663-9670

60. Sun J (1993) Effects of vertical distribution of water vapour and temperature on total column water vapour retrieval error. J Geophys Res 98(C4):7069-7079

61. Trenberth $\mathrm{KE}$, Jones PD, Ambenje P, Bojariu R, Easterling D, Klein Tank A, Parker D, Rahimzadeh F, Renwick JA, Rusticucci M, Soden B, Zhai P (2007) Observations: Surface and Atmospheric Climate Change. In: Solomon S, Qin D, Manning M, Chen Z, Marquis M, Averyt KB, Tignor M, Miller HL (eds) Climate Change 2007: The Physical Science Basis. Contribution of Working Group I to the Fourth Assessment Report of the Intergovernmental Panelon Climate Change. Cambridge Univ. Press, Cambridge

62. Trenberth KE, Oslon GJ (1988) Intercomparison of NMC and ECMWF global analysis: 1980-1986. NCSR Technical note 301

63. USLC (1991) Nigeria: A Country Study: Helen Chapin Metz, ed. Helen Chapin Metz, ed. GPO for the Library of Congress (USLC), Washington. http://countrystudies.us/nigeria/. Accessed on 19 May 2019 
64. Vey S, Dietrich R, Rülke A, Fritsche $M$, Steigenberger $P$, Rothacher M (2010) Validation of precipitable water vapour within the NCEP/DOE reanalysis using global GPS observations from one decade. https://doi.org/10.1175/2009JCLI2787.1

65. Vey S, Dietrich R (2008) Validation of the atmospheric water vapour content from NCEP using GPS observations over Antarctica. In: Capra A, Dietrich R (eds) Geodetic and geophysical observations in Antarctica: an overview in the IPY perspective. Springer, New York, pp 125-135

66. Watkins T, Silicon Valley, Tornado Alley USA (2018) The role of anthropogenic water vapour in earth's climate. San José State University. http://www.sjsu.edu/faculty/watkins/watervapou r01.htm. Accessed on 20 Nov 2018
67. Wang JR, Manning W (2003) Retrievals of low integrated water vapour using MIR and SSM/T-2 measurements. IEEE Trans Geosci Remote Sens 41:630-639

68. Wittmeyer IL, Vonder Haar HT (1994) Analysis of the Global ISCCP TOVS water vapour climatology. J. Clim 7:325-333

Publisher's Note Springer Nature remains neutral with regard to jurisdictional claims in published maps and institutional affiliations. 